\title{
Um diálogo com o patrimônio cultural brasileiro
}

Ao longo de sua atuação, a cultura sempre foi um tema presente nas atividades desenvolvidas pelo CENPEC. A experiência consolidada em quase duas décadas de trabalho levou a organização a inaugurar, em 2004, a área de Educação e Cultura, que trata de articular as noções de cultura, identidade e patrimônio cultural na efetivação de uma educação voltada para a cidadania.

As diretrizes da área Educação e Cultura do CENPEC, cujo "material de trabalho" é constituído pelas diferentes dimensões da vida cultural, foram definidas a partir das premissas relacionadas no texto "Por que Educação e Cultura?”. Essas proposições refletem o compromisso do CENPEC de estabelecer um diálogo com o patrimônio cultural brasileiro, atuando de modo interdisciplinar na integração entre educação e cultura.

A formação de cidadãos participativos na sociedade brasileira implica a maneira de relacionar educação e cultura. 0 fortalecimento de diferentes grupos e de suas culturas possibilita uma maior atuação e participação para se alcançar uma educação de qualidade na defesa dos direitos e na formulação de reivindicações. Acreditamos que o reconhecimento das diferenças é condição para se alcançar uma maior igualdade social.

Os objetivos, princípios, foco e ações, descritos em seguida, orientam o trabalho inaugural da área Educação e Cultura do CENPEC, o projeto Terra Paulista: histórias, arte, costumes.

\section{Objetivos}

1. Discutir e integrar as noções de cultura, identidade e patrimônio cultural como os fundamentos para a concretização de uma educação para a cidadania, apoiada no tripé: educação, cultura e proteção social.

\section{8}

Partimos do pressuposto de que o direito à educação e à proteção social deve estar articulado a uma política cultural fundamentada no reconhecimento das diferenças, da heterogeneidade das pessoas e dos grupos, numa política social e econômica de promoção da igualdade de direitos e de redistribuição da riqueza material e simbólica socialmente gerada.

A cidadania tem, como princípios, o direito, o dever e a participação nas instâncias de decisão sobre os rumos da coletividade. Portanto, ela apenas se realiza efetivamente com a afirmação, no espaço público, dos diferentes patrimônios dessa coletividade. Ou seja, a cidadania implica acesso aos meios para que os diferentes grupos sociais possam fazer circular e reproduzir sentidos, valores e costumes, recolocando no tempo e no espaço os laços formadores dos sujeitos, que os ligam a histórias, pessoas, lugares, processos e estruturas sociais.

A construção de relações cidadãs, marcadas pelo reconhecimento da diversidade, requer a afirmação, segundo a qual, as identidades são construídas e transformadas ao longo do tempo, e se fundamentam no reconhecimento da partilha de elementos de patrimônio, no reconhecimento daquilo que enlaça nossas biografias, na percepção de que temos, como parte de nós, traços culturais que os outros também têm.

Somos um país mestiço, São Paulo é um estado mestiço. Reconhecer a diferença como algo intrínseco a cada um de nós é admitir que incorporamos características, valores ou costumes de grupos europeus, asiáticos, indígenas, africanos e de outras regiões do Brasil. Articular o reconhecimento da diferença com a promoção da igualdade de direitos é perceber essas diferenças com os mesmos valores e direitos com os quais fazemos circular os modos de atribuir sentido ao mundo e ocupamos os espaços sociais: públicos, virtuais e, especialmente, na mídia. 
2. Contribuir para a inclusão de elementos do patrimônio cultural, material e imaterial e das questões relativas ao patrimônio natural na seleção dos conteúdos a serem transmitidos pela escola e por outras instâncias educacionais.

Uma vez que a escola tem um papel central na transmissão dos saberes socialmente valorizados, cabe debater como os diferentes elementos do patrimônio são integrados ao seu funcionamento.

De que maneira as escolas incorporam as manifestações culturais e artísticas dos grupos negros; as diversas modalidades de festas religiosas e profanas; os múltiplos aspectos da cultura caipira, sertaneja ou cabocla; os modos de vida e as histórias de protagonistas das camadas populares? Como é pensada a questão do meio ambiente no que se refere aos cuidados com a natureza e ao seu papel para a organização da vida social?

Uma rediscussão sobre os olhares para a nossa história e cultura e os seus protagonistas e sobre o meio ambiente permite a abertura de espaço e condições para que esses conteúdos sejam trabalhados, nas atividades educacionais, como parte legítima e valorizada do nosso patrimônio.

3. Valorizar as culturas locais por meio do conhecimento do seu patrimônio, do seu saber fazer e da escuta dos sujeitos protagonistas dessas manifestações, respeitando as diferentes temporalidades históricas, a diversidade e a pluralidade cultural. Ao mesmo tempo, contribuir para o diálogo entre esses valores e os princípios universais para a construção efetiva da democracia.

A valorização do diferente envolve a consideração da diversidade, resultando na inclusão dos diferentes legados culturais na vida pública, com igual importância e valor.

Valorizar a diferença é dar espaço aos sujeitos locais e buscar entender suas histórias, costumes e manifestações artísticas, de modo a valorizá-las, estabelecendo relações com seu entorno, com a própria região, com outras regiões e com o contexto mundial.

4. Articular o passado e o presente por meio do conhecimento do processo de formação histórica, reconhecendo o passado como integrante da história de cada um, com marcas culturais que permitem a construção de laços de identidade e o sentimento de pertencimento a uma cultura e a um lugar.
O estudo do passado possibilita a compreensão e a ressignificação do presente e o reconhecimento de sujeitos, grupos, valores e processos sociais como integrantes e formadores do presente. Por exemplo, permite reconhecer e valorizar a origem indígena do paulista ou o papel das mulheres paulistas ao longo da história, além da presença desses legados na sociedade contemporânea.

A história permite estabelecer relações entre os costumes e valores integrantes da nossa trajetória coletiva com outros processos históricos e com elementos formadores da história de cada um. Trata-se de viver um espaço de pertencimento, no qual a modernidade não consiste em começar tudo de novo, iniciar do nada, mas em sentir-se enraizado, pertencendo, apropriando e reelaborando a herança das gerações anteriores. 0 grande e necessário desafio é ser moderno a partir dos legados que nos formam, legitimando a contemporaneidade.

5. Contribuir, por meio do conhecimento de uma dada região e de sua articulação com as questões nacionais e globais, para o desenho de políticas públicas mais adequadas e próximas das realidades nas quais se atua.

Levando-se em conta as histórias, os valores e os costumes que conformam as diferentes regiões e suas relações com o todo, é possível desenhar projetos e políticas públicas mais adequados à realidade na qual se intervém.

6. Contribuir para fortalecer, na opinião pública, representações sobre a formação sociocultural do Estado de São Paulo, reconhecendo, nas múltiplas e diversas experiências constituintes do patrimônio, elementos passíveis de atualização no presente e no futuro.

Os modos de olhar para a história e de selecionar os saberes socialmente valorizados são definidos a partir das modalidades de transmissão desses conhecimentos. Portanto, esse debate deve acontecer entre um público amplo, ao mesmo tempo conhecido e difuso.

0 debate ocorre com os sujeitos específicos e também se volta a discursos conhecidos e estruturados que são referências legitimadas para os modos de pensar a história. Como exemplos dessas referências, temos a representação da São Paulo quatrocentona e bandeirante, como a locomotiva do Brasil, terra do progresso e tantos outros discursos, presentes em nosso cotidiano. 


\section{Princípios}

- Inclusão do patrimônio cultural das diferentes camadas e grupos sociais no acervo que compõe o patrimônio cultural brasileiro.

- Respeito às diferentes temporalidades históricas e pluralidade cultural que convivem, muitas vezes, no mesmo espaço e tempo.

- Valorização das diferenças culturais e mestiçagens.

- Desconstrução de uma visão preconceituosa em relação a personagens importantes da história brasileira.

- Revisão da história oficial que se perpetuou com mistificações e atos de discriminação e violência.

\section{Foco}

A inclusão social é considerada, na relação educação e cultura, como princípio norteador para se alcançar a melhoria da educação pública e o aprimoramento das políticas sociais. Nesse sentido, considera-se fundamental a inclusão dos diferentes legados dos patrimônios natural, material e imaterial, de modo que a instância local esteja articulada com as instâncias mais abrangentes, como a regional, nacional e global. Para a inclusão desses legados, são valores centrais o seu reconhecimento e a sua valorização, considerando-os iguais no direito de difundir seus sentidos e modos de vida.

\section{Ações}

- Conhecimento, reconhecimento e divulgação dos diferentes espaços educativos.

- Formação continuada dos agentes culturais, sociais e educacionais.

- Construção de metodologias de trabalho.

\section{Meios de atuação}

- Elaboração de projetos com alcance amplo, de modo a difundir essas idéias por meio de diversos suportes, como livros, documentos, revistas, exposições, Internet, CD-ROM, entre outros.

- Participação em diferentes eventos e busca de apoio nas diferentes mídias para concretização dessa divulgação.

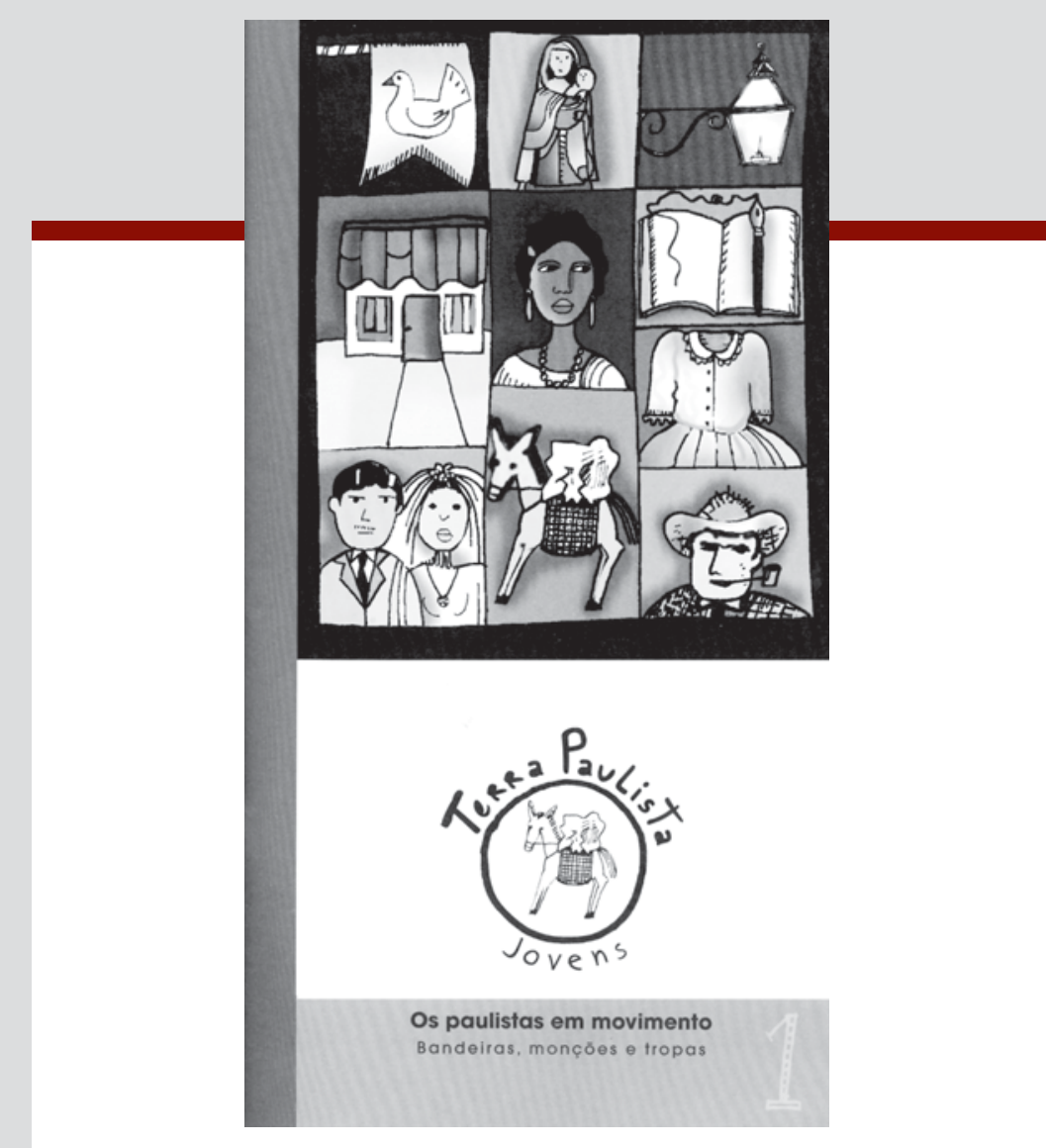

\section{Coleção Terra Paulista}

volume 1 Os paulistas em movimento Bandeiras, monções e tropas

volume 2 Açúcar, café, escravos e imigrantes A vida nas fazendas paulistas

volume 3 A vida caipira em São Paulo Permanência no tempo

volume 4 Famílias paulistas Múltiplos arranjos

volume 5 Moradias dos paulistas Das fazendas às vilas operárias

volume 6 Costumes no interior paulista Alimentação e vestuário

volume 7 A formação da metrópole A capital e as relações com o interior

volume 8 A literatura do interior Causos, contos e romances

volume 9 Artes plásticas e artesanato Cores e formas do interior

volume 10 As celebrações populares Festa, dança e música

vídeos Vale do Médio Tietê Vale do Paraíba 


\section{Histórias, arte, costumes.}

Ao investigar, registrar e valorizar o patrimônio cultural do interior paulista, não pretendemos propor uma volta ao passado e muito menos definir as tradições, os costumes e os valores paulistas como os melhores e mais corretos. Longe disso, o nosso intuito é estimular um olhar crítico - e, ao mesmo tempo, humanizado - para a formação sociocultural do interior paulista.

Esse olhar nasce da percepção de que, na representação hegemônica sobre o Estado de São Paulo, valorizara-se o moderno, o industrial, o urbano, o século XX republicano ou as raízes bandeiristas do período colonial. Com essas idéias, o passado paulista tornou-se sinal do atraso e da desordem; o rural passou a simbolizar o precário. 0 homem simples e todo o seu vasto legado cultural de raízes imemoriais foram representados como a negação da modernidade, a antítese da civilização e do progresso.

Esses legados, no entanto, não desapareceram. Eles continuam a se reproduzir, ora fortes e intensos, ora enfraquecidos e residuais. Outras experiências e modos de existir, integrantes da história dos paulistas, não entraram, sobretudo, naquilo que não coube na representação de São Paulo como uma locomotiva do progresso.

Tanto nas investigações sobre o passado quanto nos registros de aspectos da vida cultural do presente, pretendeu-se a compreensão dos diferentes modos de viver dos paulistas de diferentes regiões. 0 que eles fazem? O que pensam sobre si e sobre os outros? Como olham para sua própria história?

Procurou-se pelos protagonistas dessa história e pelo seu olhar sobre o que fazem. Protagonistas humanizados e, portanto, pessoas comuns.

Nossa preocupação constante foi no sentido de olhar para a história a partir desses personagens. Assim, a diversidade cultural paulista foi um tema central e sempre presente nos vários grupos culturais que povoaram e definiram a gente paulista, e nos diferentes influxos que marcaram sua história.

São tropeiros, bandeirantes, monçonenses, fazendeiros, sitiantes, escravos, indígenas, religiosos, colonos, camadas médias urbanas, empresários, imigrantes estrangeiros e migrantes de outras regiões do Brasil que se relacionaram, entraram em conflito, fizeram acordos e definiram o legado paulista que nos formou. Fazem parte de nossa formação influências de outras regiões do Brasil e de povos asiáticos e europeus - ibéricos, italianos, franceses, ingleses e outros -, além das marcas do desenvolvimento econômico e político norte-americano.

A terra paulista, mostrada nos produtos do projeto, é uma terra plural, feita por gente muito diferente. Feita por pessoas que têm em si mesmas - em suas ambigüidades, riquezas e contradições - a expressão dessa diversidade.

Valorizamos toda essa diversidade e pluralidade de experiências e de legados formadores do imenso patrimônio cultural paulista. Para nós, a configuração dos modos de ser paulista não é algo cristalizado e nem a idealização de uma época da história isolada e pura, como a marca de uma pretensa originalidade.

É desse modo que pretendemos responder ao desafio contemporâneo de fortalecer práticas de convívio com o diferente, reconhecendo no seu passado e no seu presente um acúmulo de experiências possíveis de enriquecer as nossas vidas e fornecer novas possibilidades para a construção do futuro.

Por meio do olhar para a história e da investigação sobre nós mesmos, o diferente e os traços específicos podem ser reconhecidos como nossa riqueza. A valorização de nosso patrimônio e a abertura para novas influências podem ser a chave para darmos conta de um imenso desafio contemporâneo: recolocar o tradicional na modernidade e, ao mesmo tempo, transformar essas tradições com os outros tantos legados que se apresentam a nós.

Portanto, é dessa maneira que a área Educação e Cultura do CENPEC pretende intervir no debate público sobre a história e o patrimônio cultural. E, se assim fazemos, é porque entendemos todo o potencial dessa ação na formação de representações sobre toda a sociedade e, por extensão, sobre o que deve ou não ser ensinado e reproduzido na história. 